\title{
СЕЛЬСROXO3SЙСТВEHHЫE HAУRИ
}

\author{
ЭКОЛОГО-МЕЛИОРАТИВНАЯ ОЦЕНКА СОДЕРЖАНИЯ ТЯЖЕЛЫХ МЕТАЛЛОВ В ВОДЕ \\ МАГИСТРАЛЬНОГО КАНАЛА ОСУШИТЕЛЬНОЙ СИСТЕМЫ РЯЗАНСКОЙ МЕЩЕРЫ \\ DOI: $10.31618 /$ ESU.2413-9335.2020.10.74.800 \\ Ильинский Андрей Валерьевич \\ кандидат с/х наук, доцент, \\ ФГБНУ «ВНИИГиМ им. А.Н. Костякова»,
}

2. Рязань

\section{ECOLOGICAL AND MELIORATIVE ASSESSMENT OF HEAVY METALS CONTENT IN WATER OF THE MAIN CHANNEL OF THE RYAZAN MESHCHERA DRAINAGE SYSTEM}

\author{
Ilinskiy Andrey \\ candidate of agricultural sciences, associate professor \\ Federal State Scientific Institution \\ «All-Russian research institute for hydraulic engineering \\ and reclamation of A.N. Kostyakov»,
}

Ryazan

\section{АННОТАЦИЯ}

В статье представлены результаты экологического мониторинга содержания тяжелых металлов (меди, цинка, свинца и кадмия) в воде магистрального канала мелиоративного объекта «Тинки-2». Установлено, что на выходе с объекта концентрации элементов меньше, чем на входе мелиоративной системы, меди на $41 \%$, цинка - на 46\%, свинца - на $86 \%$ и кадмия - на $37 \%$. На основании эколого-мелиоративной оценки содержания тяжелых металлов в воде даны рекомендации по их использованию во внутрихозяйственных целях и применению водооборотных систем в сельском хозяйстве.

\section{ABSTRACT}

The article presents the results of environmental monitoring of the content of heavy metals (copper, zinc, lead and cadmium) in the water of the main channel of the tinki-2 reclamation facility. It was found that the concentration of elements at the exit from the object is less than at the entrance of the reclamation system, copperby $41 \%$, zinc-by $46 \%$, lead-by $86 \%$ and cadmium-by $37 \%$. Based on the ecological and meliorative assessment of the content of heavy metals in water, recommendations are given for their use for on-farm purposes and the use of water circulation systems in agriculture.

Ключевые слова: водооборотные системы, качество воды для орошения, магистральный канал, мелиорированные земли, осушенные земли, поверхностные воды, тяжелые металлы, экологическая безопасность, экологический мониторинг.

Keywords: water circulation systems, irrigation water quality, main canal, reclaimed land, drained land, surface water, heavy metals, environmental safety, environmental monitoring.

Своеобразный компонент географической среды, малые реки в значительной степени выполняют функции регулятора водного режима определенных ландшафтов, поддерживая равновесие и осуществляя перераспределение влаги. К тому же они определяют гидрологическую и гидрохимическую специфику средних и крупных рек. Главной особенностью формирования стока малых рек является очень тесная их связь с ландшафтом бассейна, что и обусловливает легкую уязвимость этих водных артерий - не только при чрезмерном использовании водных ресурсов, но и при освоении водосбора $[2,6]$. Одним из отходов гидромелиоративных систем являются коллекторно-дренажные воды, способные приводить к загрязнению и последующей деградации компонентов природной среды $[5,7,8]$. К важным загрязняющим окружающую среду веществам относятся тяжелые металлы [4, 10]. Выпадение кислотных осадков способствует повышению кислотности и переходу металлов из сорбированного состояния в свободное.
Естественными источниками поступления свинца в поверхностные воды являются процессы растворения эндогенных и экзогенных минералов. Существенными факторами снижения концентрации свинца в воде адсорбция его взвешенными веществами и осаждение в донные отложения, он также способен извлекаться и накапливаться гидробионтами. Кадмий поступает в природные воды при выщелачивании почв, полиметаллических и медных руд, в результате разложения водных организмов, способных его накапливать. Снижении концентрации растворенных соединений кадмия происходит за счет процессов сорбции, выпадения в осадок гидроксида и карбоната кадмия и потребления их водными организмами [3].

Загрязняющие вещества нормируются по лимитирующему показателю вредности (ЛПВ), под которым понимают наибольшее отрицательное влияние, оказываемое данными веществами. Вода считается чистой, если ее состав и свойства ни по одному из показателей не выходят за пределы 
установленных нормативов, а содержание вредных веществ не превышает предельно-допустимых концентраций (ПДК). При наличии в воде нескольких веществ с одинаковым ЛПВ, сумма отношений их концентраций к соответствующим ПДК не должна превышать единицы [9].

Химический состав дренажных вод весьма разнообразный и во многом зависит от регионального галогеохимического режима [8]. В этой связи, для оценки химического состава поверхностных вод при проведении стационарных эколого-мелиоративных наблюдений на мелиоративном объекте «Тинки-2» (Рязанская область Рязанский район) осуществлялся периодический отбор проб воды из магистрального канала на стационарных постах наблюдений: (3 поста: вход и выход канала, дрена)

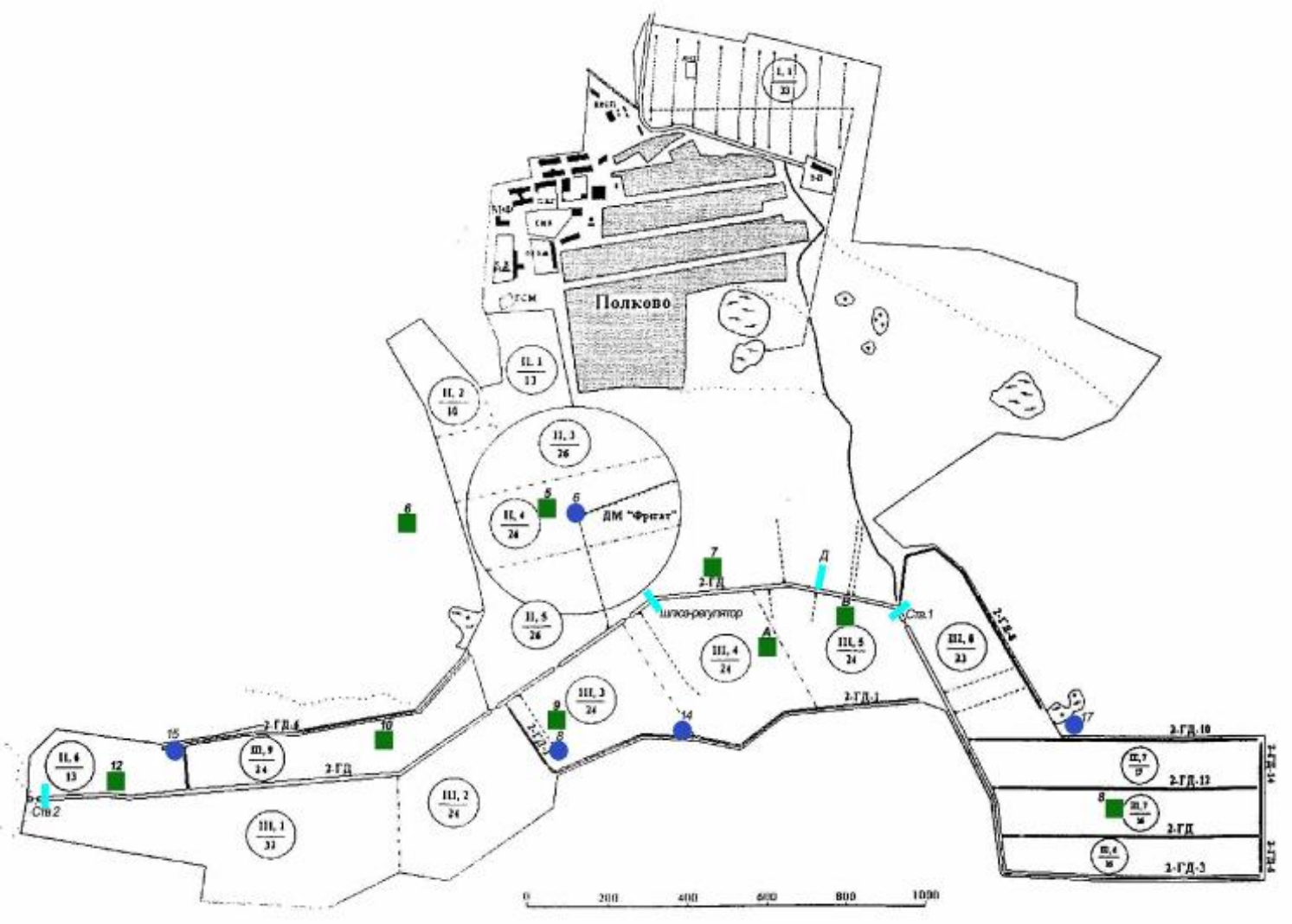

Условные обозначения:

- гидропост

Рисунок 1. Схема расположения гидропостов на магистральном канале осушительно-увлажнительной системь «Тинки-2»

Отбор проб поверхностных вод из сети стационарных постов наблюдений осуществлялся в соответствии с ГОСТ Р51592-2000. В отобранных пробах по общепринятым методикам определено содержание тяжелых металлов (медь, цинк, свинец и кадмий). 


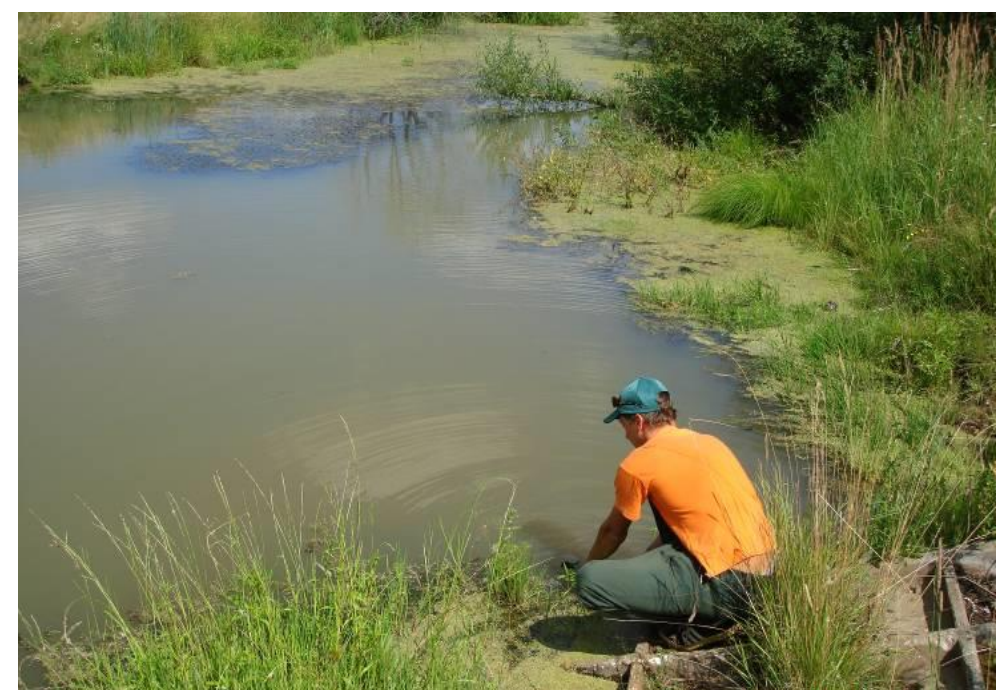

Рисунок 2. Отбор пробы воды из магистрального канала мелиоративной системы «Тинки-2»

Обобщенные результаты мониторинговых наблюдений за содержанием тяжелых металлов в воде магистрального канала осушительно- увлажнительной системы «Тинки-2» представлены в таблице 1.

Таблица 1

Результаты изучения содержания тяжелых металлов в воде магистрального канала мелиоративного объекта «Тинки-2»

\begin{tabular}{|c|c|c|c|c|}
\hline \multirow{2}{*}{$\begin{array}{c}\text { Место отбора проб } \\
\text { воды }\end{array}$} & \multicolumn{4}{|c|}{ Концентрация в воде элемента, мкг/л } \\
\hline & медь & цинк & свинец & кадмий \\
\hline канал на входе в объект & $\frac{2,1-144,0}{51,7}$ & $\frac{71,0-92,0}{81,0}$ & $\frac{2,5-45}{21,5}$ & $\frac{0,1-0,5}{0,27}$ \\
\hline дрена & $\frac{1,0-5,6}{3,3}$ & $\frac{19,0-43,0}{11,5}$ & $\frac{2,3-47,0}{17,8}$ & $\frac{0,1-0,2}{0,15}$ \\
\hline $\begin{array}{c}\text { канал на выходе из } \\
\text { объекта }\end{array}$ & $\frac{1,5-82,0}{30,4}$ & $\frac{5,0-115,0}{43,3}$ & $\frac{1,0-6,0}{3,1}$ & $\frac{0,1-0,3}{0,17}$ \\
\hline ПДК, мкг/л * & 1000 & 1000 & 10 & 1 \\
\hline ПДК & 200 & 1000 & 30 & 10 \\
\hline
\end{tabular}

Примечание: * - над чертой пределы значений, под чертой средние значения концентраций элемента; ** - по данным ГН 2.1.5.1315-03; ${ }^{* * *}$ - ПДК в оросительной воде, по данным С.Я. Бездниной [1].

Анализ содержания тяжелых металлов в воде магистрального канала мелиоративного объекта «Тинки-2» (табл. 1) показал, что на выходе с объекта концентрации элементов меньше, чем на входе мелиоративной системы, меди - на 41\%, цинка - на $46 \%$, свинца - на $86 \%$ и кадмия - на $37 \%$. При этом наибольшая дифференциация наблюдается в летне-осенний период, что во многом связано как с адсорбцией их взвешенными веществами и осаждением в донные отложения, так и с концентрированием тяжелых металлов высшей водной растительностью по мере продвижения воды по каналу. Результаты мониторинговых исследований также показали, что содержание в воде магистрального канала меди, цинка и кадмия не превышает значений предельно допустимых концентраций химических веществ в воде водных объектов хозяйственно-питьевого и культурнобытового водопользования. По содержанию свинца в воде (на входе канала мелиоративного объекта и из дрены) наблюдается превышение ПДК в 2,2 и 1,8 раза соответственно. Выполненный для металлов с одинаковым ЛПВ расчет сумм отношений средних концентраций элементов к соответствующим ПДК показал, что наибольшие их значения были зафиксированы в магистральном канале «на входе в объект»: для группы медь + цинк $-0,13$; для группы свинец + кадмий $-2,42$.

Оценка средних значений концентраций изучаемых элементов в воде магистрального канала по классификации тяжелых металлов и других элементов по степени опасности их содержания в воде для орошения, предложенной С.Я. Бездниной [1], показала пригодность её использования для орошения в сельском хозяйстве.

Таким образом, для экологически безопасного отведения дренажных вод в поверхностные водные объекта, а также их использования для внутрихозяйственных целей, в том числе для орошения культур, необходимо предусматривать установку сооружений по улучшения их химических характеристик, перспективным также является создание замкнутых систем водопользования в сельском хозяйстве. 


\section{Список литературы}

1. Безднина, С.Я. Экологические основы водопользования / С.Я. Безднина. - М.: ВНИИА, 2005. - 224 c.

2. Виноградов Д.В., Ильинский А.В., Данчеев Д.В. Экология агрэкосистем. - Рязань: ИП Жуков В.Ю., 2020. - 256 c.

3. Гусева Т.В., Молчанова, Заика Е.А., Лебединская Л.А. и др. Гидрохимические показатели состояния окружающей среды: справочные материалы. - М.: РХТУ им. Д.И. Менделеева, 2005. - 176 с.

4. Евсенкин К.Н., Ильинский А.В. Результаты изучения запасов воды в снежном покрове на землях Рязанской Мещеры // Евразийский Союз Ученых (ЕСУ). Ежемесячный научный журнал. 2 часть. - 2019. - 11 (68). - С. 33-35.

5. Захарова О.А., Евсенкин К.Н. Характеристика грунтовых вод на мелиорированном агроландшафте // Вестник Рязанского государственного агротехнологического университета им. П.А. Костычева. - 2016. - № 2 (30). - С. 18-22.

6. Ильинский А.В., Виноградов Д.В., Данчеев Д.В. Экологические основы природопользования: учебное пособие // Рязань: ФГБОУ ВО РГАТУ, 2017. - $128 \mathrm{c}$.

7. Ильинский А.В., Игнатенок В.А. Результаты мониторинга сбросных и коллекторно-дренажных вод длительно используемых осушенных земель на примере мелиоративной системы «Тинки-2» Рязанской области // Проблемы рационального использования природохозяйственных комплексов засушливых территорий сб. науч. тр. науч. Ред. Зволинский В.П. - ФГБНУ «ПНИИАЗ», 2015. - С. 74-77.

8. Кирейчева Л.В., Юрченко И.Ф., Яшин В.М. Научные основы создания и управления мелиоративными системами в России. - М.: ФГБНУ «ВНИИ агрохимии», 2017. - 296 с.

9. Нейтрализация загрязненных почв: монография / под ред. Ю.А. Мажайского. - Рязань: Мещерский филиал ГНУ ВНИИГиМ Россельхозакадемии, 2008. - 528 с.

10. Орлов Д.С., Садовникова Л.К., Лозановская И.Н. Экология и охрана биосферы при химическом загрязнении // Учебное пособие для химических, химико-технологических и биологических спец. вузов. - М.: Высшая школа, 2002. -234 c.

УДК: 632.65.7. 633.1

\section{БИОЛОГИЧЕСКАЯ ЭФФЕКТИВНОСТЬ ПРЕПАРАТА СПИДЕР ДУО $28 \%$ К.С. ПРОТИВ РЖАВЧИННОГО КЛЕЩА НА ТОМАТЕ}

DOI: $\frac{10.31618 / \text { ESU.2413-9335.2020.10.74.805 }}{\text { Муминова P., }}$
Tаджсиева M.
Ташкентский государственный аграрный университет,
Узбекистан, Ташкент.

\section{АННОТАЦИЯ}

На современном этапе развития сельскохозяйственного производства Республики Узбекистан повышение урожайности сельскохозяйственных культур, в том числе и томата является очень важной. Однако томат, как и многие сельскохозяйственные культуры, подвержен заселению многих вредных насекомых, опаснейшими из которых являются ржавчинный клещ. Против них используются несколько методов борьбы. Но нужно отметить, что наиболее эффективным является химический метод, хотя он имеет ряд недостатков. С целью свести к минимуму отрицательные последствия его, необходим грамотный подход. Одним из способов решения этой задачи является подбор наиболее эффективных, менее токсичных и быстродействующих препаратов. С этой целью нами испытан новый препарат препарата Спидер Дуо 28\% к.с. против ржавчинного клеща на Томата защищенного грунта.

\section{ABSTRACT}

At the present stage of the development of agricultural production in the republic of Uzbekistan, increasing the yield of crops, including tomato, is very important. However, tomato, like many crops, is susceptible to the settlement of many harmful insects, the most dangerous of which are the rust mite. Several methods of struggle are used against them. But it should be noted that the chemical method is the most effective, although it has several disadvantages. In order to minimize its negative consequences, a competent approach is needed. One way to solve this problem is to select the most effective, less toxic, and fast-acting drugs. For this purpose, we tested a new preparation of the drug spider duo $28 \%$ k.s. against a rust tick on tomato sheltered ground.

Ключевые слова: Самка, самец, нимфа, личинка, фаза, цикл, меры борьбы.

Keywords: female, male, nymph, larva, phase, cycle, control measures.

Ржавчинный клещ томата (Aculops licopersici Massee.) его также называют бурым или ржавчинным помидорным клещиком. Охотно заселяется и питается на томатах, картофеле, паслёне чёрном, баклажане, плохо приспосабливается на перце. Большой вред наносит не только в защищённом, но и в открытом грунте. Это очень мелкий, невидимый невооруженным глазом сосущий вредитель. В отличие от других клещей имеет не четыре, а две пары ног. Клещ имеет удлиненное тело, состоящее из головогруди и кольчатого брюшка, две пары ног, 